\title{
Key prognostic factors for EGFR-mutated non-adenocarcinoma lung cancer patients in the Japanese Joint Committee of Lung Cancer Registry Database
}

\section{Keigo Kobayashi $^{\mathrm{a}, *}$, Kenzo Soejima ${ }^{\mathrm{a}}$, Koichi Fukunaga ${ }^{\mathrm{a}}$, Yasushi Shintani ${ }^{\mathrm{b}}$, Ikuo Sekine ${ }^{\mathrm{c}}$, Takehito Shukuya $^{\mathrm{d}}$, Koichi Takayama ${ }^{\mathrm{e}}$, Akira Inoue ${ }^{\mathrm{f}}$, Isamu Okamoto $^{\mathrm{g}}$, Katsuyuki Kiura ${ }^{\mathrm{h}}$, Kazuhisa Takahashi ${ }^{\mathrm{d}}$, Nobuyuki Yamamoto ${ }^{\mathrm{i}}$, Yuichi Takiguchi ${ }^{\mathrm{j}}$, Etsuo Miyaoka ${ }^{\mathrm{k}}$, Meinoshin Okumura ${ }^{1}$, Ichiro Yoshino ${ }^{\mathrm{m}}$, on behalf of the Group on behalf of the Japanese Joint Committee of Lung Cancer Registry}

\footnotetext{
${ }^{a}$ Division of Pulmonary Medicine, Department of Medicine, Keio University School of Medicine, Tokyo, Japan

${ }^{\mathrm{b}}$ Department of General Thoracic Surgery, Osaka University Graduate School of Medicine, Osaka, Japan

${ }^{c}$ Department of Medical Oncology, Faculty of Medicine, University of Tsukuba, Tsukuba, Japan

${ }^{\mathrm{d}}$ Department of Respiratory Medicine, Juntendo University Graduate School of Medicine, Tokyo, Japan

${ }^{\mathrm{e}}$ Department of Respirology, Kyoto Prefectural University of Medicine, Kyoto, Japan

${ }^{\mathrm{f}}$ Department of Palliative Medicine, Tohoku University School of Medicine, Miyagi, Japan

${ }^{\mathrm{g}}$ Research Institute for Diseases of the Chest, Graduate School of Medical Sciences, Kyushu, Japan

${ }^{\mathrm{h}}$ Department of Allergy and Respiratory Medicine, Okayama University Hospital, Okayama, Japan

${ }^{\mathrm{i}}$ Third Department of Internal Medicine, Wakayama Medical University Hospital, Wakayama, Japan

${ }^{j}$ Department of Medical Oncology, Graduate School of Medicine, Chiba University, Chiba, Japan

${ }^{\mathrm{k}}$ Department of Mathematics, Science University of Tokyo, Tokyo, Japan

${ }^{1}$ Department of General Thoracic Surgery, National Hospital Organization Toneyama Hospital, Osaka, Japan

${ }^{\mathrm{m}}$ Department of General Thoracic Surgery, Graduate School of Medicine, Chiba University, Chiba, Japan
}

\section{A R T I C L E I N F O}

\section{Keywords:}

Lung cancer registry

EGFR mutation

Non-adenocarcinoma

EGFR-TKI

Prognostic factor

\begin{abstract}
A B S T R A C T
Introduction: The efficacy of epidermal growth factor receptor (EGFR)-tyrosine kinase inhibitors (TKIs) for EGFRmutated non-adenocarcinoma (ADC) non-small cell lung cancer patients is not well established. Herein, we investigated key prognostic factors influencing the efficacy of EGFR-TKIs in these patients.

Methods: A total of 12,320 lung cancer patients pathologically diagnosed in 2012 at teaching hospitals in Japan were retrospectively selected. The follow-up survey was closed in 2016.

Results: EGFR-mutated non-ADC patients were more prone to malignant pleural effusion (MPE) and distant metastasis than ADC patients ( $\mathrm{P}=0.071$ and 0.022 , respectively). EGFR-mutated ADC patients were likely to have a longer median overall survival (OS) than non-ADC patients [hazard ratio (HR) 1.3 (95\% CI, 0.97-1.8, P $=0.072)-29.5$ months (95\% CI, 27.9-31.1 months) versus 19.5 months ( $95 \%$ CI, 10.8-28.2 months) $(\mathrm{P}=$ 0.068)]. There was no significant difference in median OS between EGFR-positive ADC and non-ADC patients receiving treatment with first-generation EGFR-TKI. Among EGFR-positive non-ADC patients, the median OS was significantly longer for patients receiving EGFR-TKI treatment than for those who did not [HR 4.5 (95\% CI, 2.1-9.8, P < 0.001) - 25.5 months (95 \% CI, 8.1-42.9 months) versus 7.5 months (95 \% CI, 3.4-11.6 months) $(\mathrm{P}<0.001)$ ]. While there was no significant difference in the median OS for ADC patients with either 19 del or L858R mutations, the median OS was significantly longer for EGFR-mutated non-ADC patients with 19 del than for those with L858R mutation (HR 3.2 [95 \% CI, 1.5-6.9, P = 0.004]; it was not reached for 19 del and was 15.5 months for L858R [95 \% CI, 6.6-24.4 months], P = 0.002).

Discussion: EGFR-mutated non-ADC patients were more prone to MPE and distant metastasis. Both ADC and EGFR del19-positive non-ADC patients can benefit from EGFR-TKI treatment, whereas EGFR L858R-positive nonADC patients might require different therapeutic options.
\end{abstract}

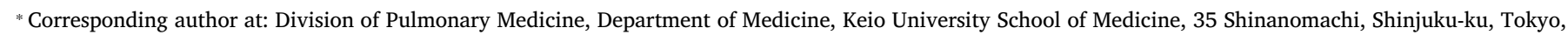
160-8582, Japan.

E-mail address: keigokbys@gmail.com (K. Kobayashi). 


\section{Introduction}

Lung cancer is the leading cause of cancer-related deaths worldwide. The discovery of epidermal growth factor receptor (EGFR) as a driver oncogene in adenocarcinoma (ADC) and the discovery of the efficacy of tyrosine kinase inhibitors (TKIs) in patients with EGFR mutations have revolutionized lung cancer therapy [1-4].

The number of EGFR-mutated ADC patients is relatively high, while non-ADC patients harboring EGFR mutations are scarce [5,6]. Because of the low frequency of EGFR-mutated non-ADC non-small cell lung cancer (NSCLC) cases, there is little evidence on the efficacy of EGFRTKIs on the overall survival (OS) of these patients. Generally, the effect of EGFR-TKIs on these patients is known to be limited; however, some patients have good response to some extent [7].

The aims of this study were, first, to investigate the efficacy of EGFR-TKIs on OS of EGFR-mutated non-ADC patients through comparison with EGFR-mutated ADC patients, and second, to identify the key prognostic factors influencing the efficacy of first-generation EGFRTKIs (gefitinib or erlotinib) for these patients.

The present study is the sixth registry study of cases in the Japanese Joint Committee of Lung Cancer Registry (JJCLCR) history in which data of lung cancer patients pathologically diagnosed in 2012 were collected.

\section{Materials and methods}

\subsection{Study population}

The JJCLCR performed a nationwide retrospective study of lung cancer patients diagnosed in 2012, who received non-surgical treatment. The committee asked 846 teaching institutions in Japan to join this study, among which 314 institutions (37.1\%) participated. A total of 14,260 patients were considered as study subjects. The exclusion criteria were as follows: (1) no data input, (2) stage not confirmed, (3) lost to follow-up, and (4) ineligible.

This registry was opened on January 1, 2012, and the follow-up survey was closed on April 30, 2016. The registration of patient information was performed through a website system, as described in a previous registry study [8].

The registry followed the ethical guidelines for epidemiologic studies. This study was approved by the review board of Osaka University Medical Hospital (approval No. 15,321).

\subsection{Clinical characteristics}

The following clinical characteristics were included in our analyses: age at diagnosis, gender, smoking history, ECOG performance status (PS), the presence or absence of malignant pleural effusion (MPE), distant metastasis (lung, liver, bone, brain, and adrenal gland), and types of EGFR mutations (exon 19 deletion [19 del], exon 21 L858R [L858R], and others).

Patients who reported to have never smoked in their lifetime were defined as non- smokers, those who had smoked within 1 year of diagnosis were categorized as current smokers, and the rest were considered former smokers.

\subsection{Clinical responses}

Clinical responses to EGFR-TKIs were evaluated based on interpretation of the progression report in accordance with the Response Evaluation Criteria in Solid Tumors (version 1.1) [9]. Notably, radiologists did not necessarily detail each target lesion across all the centers.

Tumor responses were defined as follows: a complete response (CR; the disappearance of all target lesions), a partial response (PR; $\geq 30.0$ $\%$ reduction in the sum of the diameters of the target lesions),
Table 1

Comparison of patient characteristics between EGFR-mutated adenocarcinoma and non-adenocarcinoma.

\begin{tabular}{|c|c|c|c|}
\hline Characteristics & $\begin{array}{l}\text { Adeno }(\mathrm{n}= \\
1709)\end{array}$ & $\begin{array}{l}\text { Non-Adeno }(\mathrm{n}= \\
77)\end{array}$ & $\mathrm{P}$ value \\
\hline Age (yr) & & & 0.785 \\
\hline Median (range) & $68.0(23-99)$ & $69.0(32-88)$ & \\
\hline Gender & & & $<0.001$ \\
\hline Male & $626(36.6 \%)$ & $44(57.1 \%)$ & \\
\hline Female & $1083(63.4 \%)$ & $33(42.9 \%)$ & \\
\hline Smoking history & & & 0.182 \\
\hline Never & $1009(59.0 \%)$ & $39(50.6 \%)$ & \\
\hline Former & $421(24.6 \%)$ & $26(33.8 \%)$ & \\
\hline Current & $279(16.3 \%)$ & $12(15.6 \%)$ & \\
\hline PS (ECOG) & & & 0.841 \\
\hline $0,1,2$ & $1548(90.6 \%)$ & $71(92.2 \%)$ & \\
\hline 3,4 & $161(9.4 \%)$ & $6(7.8 \%)$ & \\
\hline Malignant pleural effusion & & & 0.071 \\
\hline yes & $1207(70.6 \%)$ & $62(80.5 \%)$ & \\
\hline no & $502(29.4 \%)$ & $15(19.5 \%)$ & \\
\hline Distant metastasis & & & 0.022 \\
\hline yes & $1264(74.0 \%)$ & $66(85.7 \%)$ & \\
\hline no & $445(26.0 \%)$ & $11(14.3 \%)$ & \\
\hline Lung metastasis & & & 0.493 \\
\hline yes & $224(13.1 \%)$ & $12(15.6 \%)$ & \\
\hline no & $1475(86.3 \%)$ & $65(84.4 \%)$ & \\
\hline Liver metastasis & & & 0.191 \\
\hline yes & $184(10.8 \%)$ & $12(15.6 \%)$ & \\
\hline no & $1525(89.2 \%)$ & $65(84.4 \%)$ & \\
\hline Bone metastasis & & & 0.484 \\
\hline yes & $770(45.1 \%)$ & $38(49.4 \%)$ & \\
\hline no & $939(54.9 \%)$ & $39(50.6 \%)$ & \\
\hline Brain metastasis & & & 0.258 \\
\hline yes & $532(31.1 \%)$ & $19(24.7 \%)$ & \\
\hline no & $1177(68.9 \%)$ & $58(75.3 \%)$ & \\
\hline Adrenal metastasis & & & 0.371 \\
\hline yes & $126(7.4 \%)$ & $8(10.4 \%)$ & \\
\hline no & $1583(92.6 \%)$ & $69(89.6 \%)$ & \\
\hline Types of EGFR mutation & & & 0.561 \\
\hline 19 del & $853(49.9 \%)$ & $34(44.2 \%)$ & \\
\hline L858R & $753(44.1 \%)$ & $39(50.6 \%)$ & \\
\hline Others & $103(6.0 \%)$ & $4(5.2 \%)$ & \\
\hline
\end{tabular}

Abbreviations: EGFR, epidermal growth factor receptor; yr, year; PS, performance status; 19 del, exon 19 deletion; L858R, exon 21 L858R.

progressive disease (PD; $\geq 20.0 \%$ increase in the sum of the diameters of the target lesions), and stable disease (SD; insufficient shrinkage or expansion to qualify as a PR or PD). In the absence of measurable disease, unequivocal progression was defined as that required to declare clinically PD as PD.

\subsection{Data examination}

Following closure of the registration, the data were carefully examined. If inconsistent or conflicting data, double registration, incomplete information, or outliers were found, the registration office made corrections after inquiring at the respective hospitals.

\subsection{Statistical analyses}

Statistical analyses using the Pearson's chi-square test, Fisher's exact test, and student's $t$-test were performed. The survival period was calculated on the basis of the number of months from the first diagnosis to death. Survival curves were estimated according to the Kaplan-Meier method for clinical variables. Differences in survival were tested using the log-rank method. A two-sided $P<0.05$ was considered statistically significant for all the tests. All statistical analyses were performed using the SPSS software program, version 23.0 (SPSS Inc., Chicago, Illinois), for Windows. 


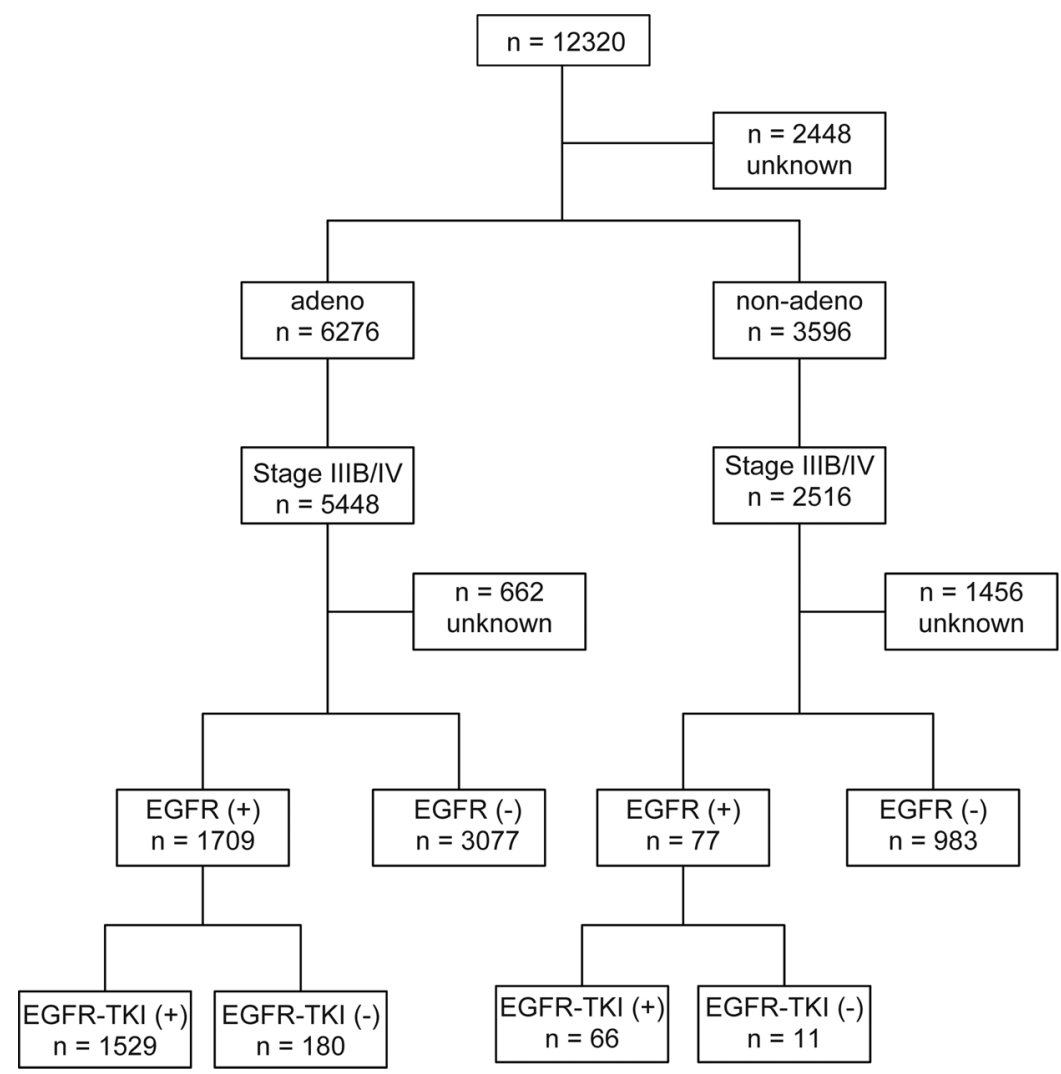

Fig. 1. Flow diagram of study participants.

Abbreviations: adeno, adenocarcinoma; EGFR, epidermal growth factor receptor; TKI, (EGFR) tyrosine kinase inhibitor; $\mathrm{n}=\mathrm{number}$.

\section{Results}

\subsection{Clinical characteristics of the study population}

A total of 14,260 patients were registered from 314 institutions in Japan. Of these, 1940 patients were excluded because of no data input ( $n=244)$, stage not confirmed $(n=188)$, lost to follow-up $(n=216)$, and ineligible $(\mathrm{n}=1292)$. Thus, finally 12,320 patients were enrolled. Of 5448 Stage IIIB or IV ADC patients, 1709 patients ( $n=1709 / 5448$, $31.4 \%$ ) had an EGFR mutation-positive status. Of these patients, 1529 patients received EGFR-TKI therapy. Of 2516 Stage IIIB or IV non-ADC patients, 77 patients ( $\mathrm{n}=77 / 2516,3.1 \%$ ) had an EGFR mutationpositive status. Of these patients, 66 patients received the EGFR-TKI therapy. The details about the proportion of each EGFR mutation in these patients are presented in Table S1.

Histological subtypes of Stage IIIB or IV EGFR-mutated non-ADC included squamous cell carcinoma (SCC, $\mathrm{n}=39$ [50.6\%]), large cell carcinoma (LCLC, $\mathrm{n}=7$ [9.1\%]), adenosquamous cell carcinoma (ASC, $\mathrm{n}=4[5.2 \%])$, undifferentiated $(\mathrm{n}=24[31.2 \%])$, and others $(\mathrm{n}=3$ [3.9\%]).

The proportions of each EGFR mutation in our study patients treated with EGFR-TKIs were as follows: ADC patients: 19 del, $49.8 \%$ (n = 761/1529), L858R, $44.8 \%(\mathrm{n}=685 / 1529)$, and others, $5.4 \%(\mathrm{n}=$ 83/1529); non-ADC patients: 19 del, $45.5 \%(\mathrm{n}=30 / 66)$, L858R, 48.5 $\%(\mathrm{n}=32 / 66)$, and others, $6.1 \%(\mathrm{n}=4 / 66)$.

The demographic data of EGFR-mutated ADC and non-ADC patients are shown in Table 1. The characteristics of the EGFR-mutated ADC patients showed that more females than males were included in the non-ADC cohort (Fisher's exact test; $P<0.001$ ). Non-ADC patients were more likely to have MPE and distant metastasis than ADC patients ( $P=0.071$ and $P=0.022$, respectively). The patient identification flowcharts are illustrated in Fig. 1.

\subsection{Comparison of the overall survival and clinical response}

The EGFR-mutated ADC patients were more likely to have a longer median OS than the non-ADC patients [hazard ratio (HR) 1.3 (95\% CI, $0.97-1.8, P=0.072$ ), 29.5 months (95 \% CI, 27.9-31.1 months) versus 19.5 months (95\% CI, 10.8-28.2 months) $(P=0.068)]$ (Fig. 2A). For patients receiving EGFR-TKI therapy, there was no significant difference in the median OS between EGFR-positive ADC and non-ADC patients [HR 1.1 (95 \% CI, 0.8-1.6, $P=0.468$ ), 29.5 months (95\% CI, 27.8-31.2 months) versus 25.5 months (95\% CI, 8.1-42.9 months) ( $P$ $=0.462$ ) ] (Fig. 2B). In addition, among EGFR-positive non-ADC patients, the median OS for patients receiving EGFR-TKI treatment was significantly longer than that of patients who did not receive the treatment [HR 4.5 (95 \% CI, 2.1-9.8, $P<0.001$ ), 25.5 months (95\% CI, 8.1-42.9 months) versus 7.5 months (95\% CI, 3.4-11.6 months) $(P<0.001)$ ] (Fig. 2C).

Although no significant difference in OS was observed between ADC patients with 19 del and those with L858R mutations (HR 1.0 [95 \% CI, $0.9-1.2, P=0.945], 29.5$ months [95 \% CI 27.1-31.9 months] and 31.5 months [95 \% CI 29.1-33.9 months], $P=0.944$ ), the median OS for EGFR-mutated non-ADC patients with 19 del was significantly longer than that of patients with the L858R mutation (HR 3.2 [95 \% CI 1.5-6.9, $P=0.004$ ], 19 del was not reached, and L858R was 15.5 months [95 \% CI 6.6-24.4 months], $P=0.002$ ) (Fig. 3A, B).

Among the EGFR-mutated non-ADC NSCLC patients treated with first-generation EGFR-TKIs (regardless of the treatment line), the CR was $6.1 \%$, PR was $45.5 \%$, SD was $18.2 \%$, and PD was $19.7 \%$.

\subsection{Clinical characteristics and treatment efficacy}

To investigate the clinical characteristics influencing the efficacy of EGFR-TKIs in EGFR-mutated non-ADC NSCLC patients, the patients who received the EGFR-TKI therapy were divided into two groups on the 
(A)

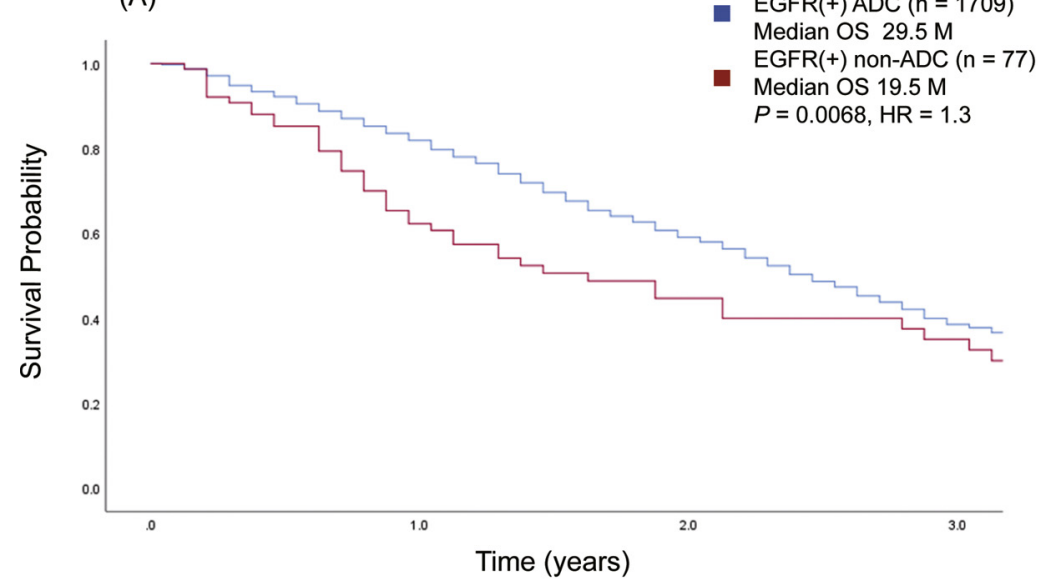

(B)

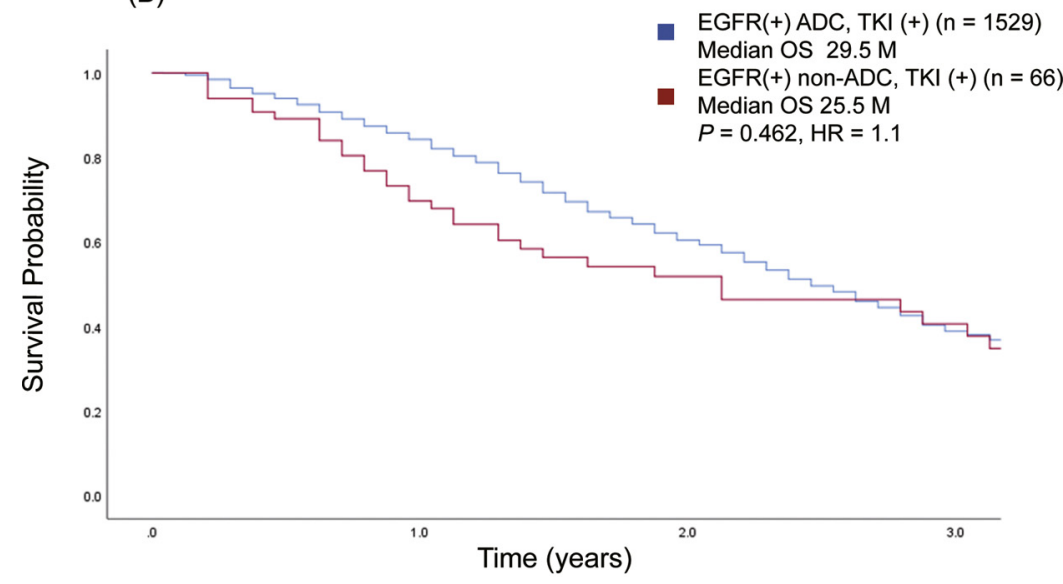

(C)

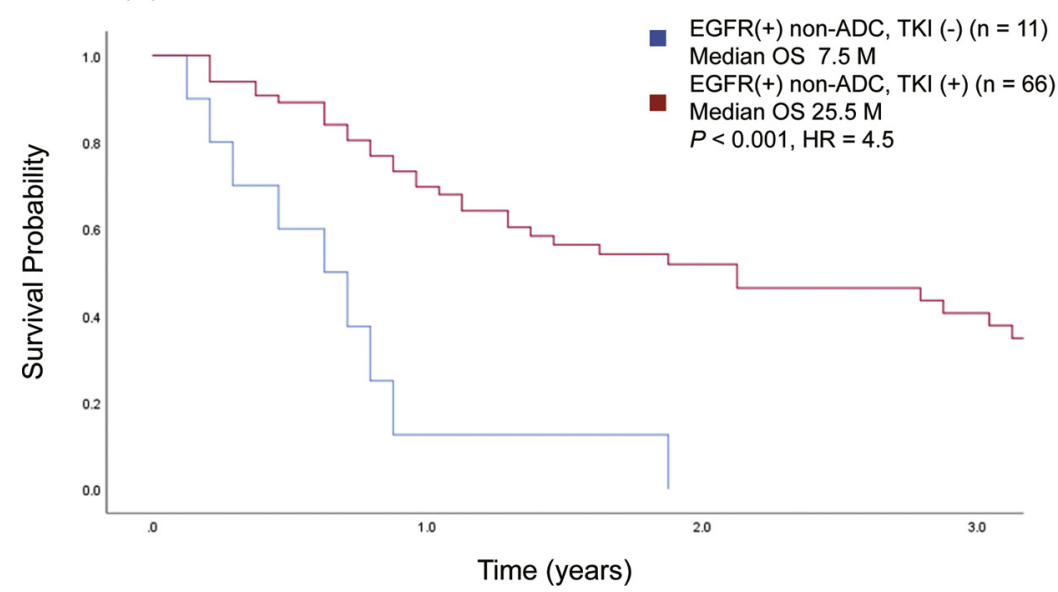

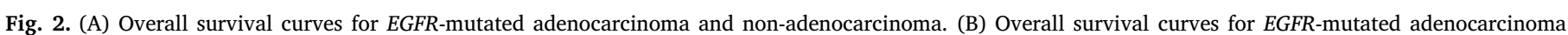

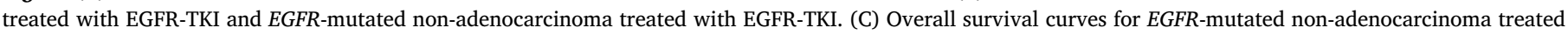
with EGFR-TKI and not treated with EGFR-TKI.

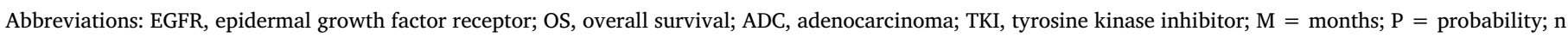
$=$ number.

basis of their response: the "response group" was defined as patients whose tumor responded to the first use of EGFR-TKI (regardless of treatment line) as a CR and a PR, and the "non-response group" was defined as patients who had achieved SD and PD. There was no significant difference in clinical characteristics between the "response group" and the "non-response group" (Table 2).

Moreover, there was no significant difference in patient characteristics between 19 del-positive and L858R-positive mutations in non-ADC patients (Table 3 ).

\section{Discussion}

The efficacy of EGFR-TKIs in non-ADC remains controversial because the number of non-ADC cases harboring EGFR mutations is 

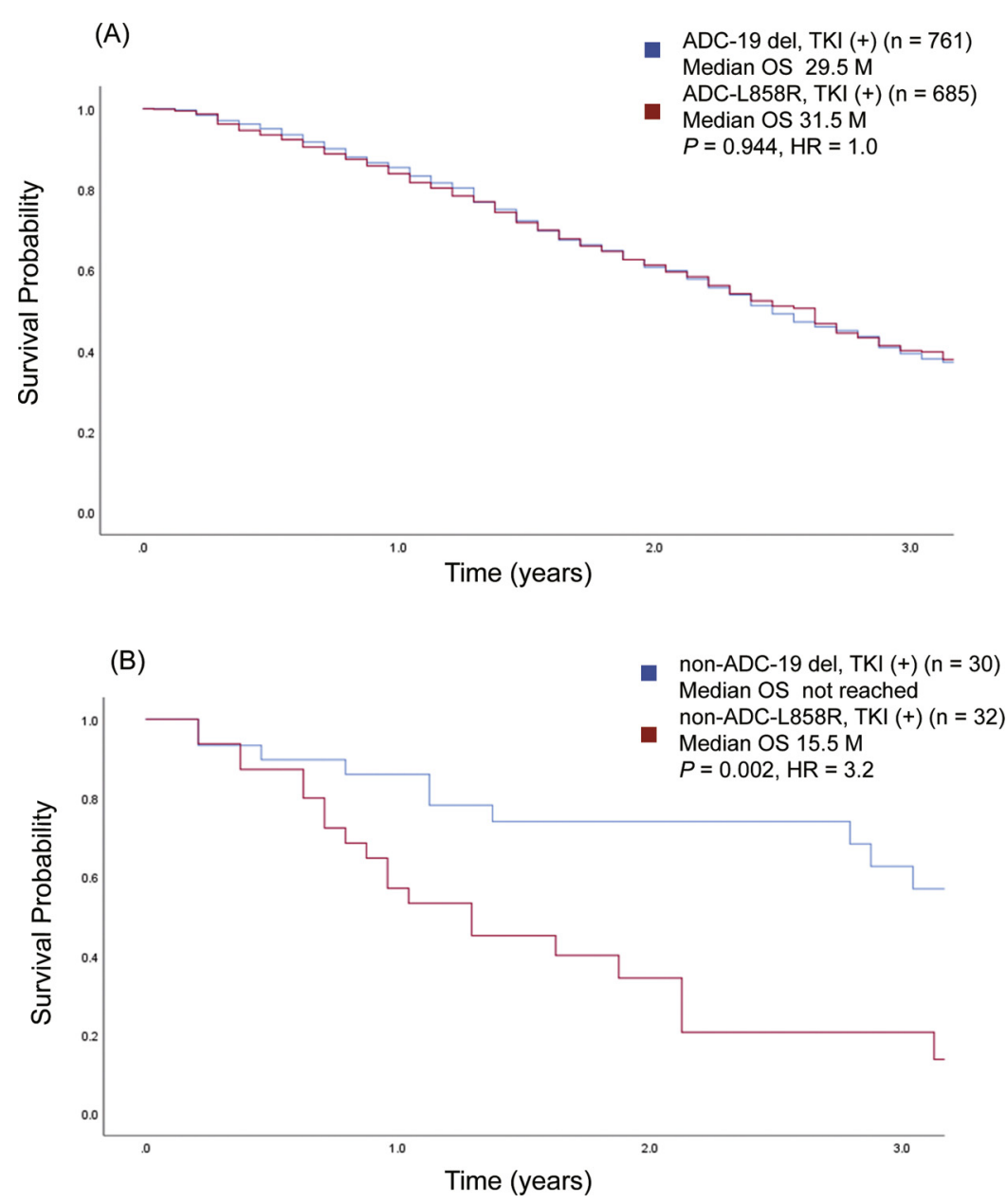

Fig. 3. (A) Overall survival curves for EGFR-mutated adenocarcinoma, with exon 19 deletion and exon 21 L858R mutations, treated with EGFR-TKI. (B) Overall survival curves for EGFR-mutated non-adenocarcinoma, with exon 19 deletion and exon 21 L858R mutations, treated with EGFR-TKI.

Abbreviations: EGFR, epidermal growth factor receptor; OS, overall survival; ADC, adenocarcinoma; 19 del, exon 19 deletion; L858R, exon 21 L858R; TKI, tyrosine kinase inhibitor; $\mathrm{M}=$ months; $\mathrm{P}=$ probability; $\mathrm{n}=$ number.

relatively smaller than of ADC cases harboring these mutations. Previous studies had a small sample size, and they assessed the efficacy by response rate (RR) and progression free survival, which were likely affected by investigator bias. The current study had a large sample size and a long follow-up period for OS. Moreover, we compared the differences between $\mathrm{ADC}$ and non-ADC, making the outcome more robust in that a lot of data and evidence is available on ADC.

For example, previous studies on ADC included more women than men in the non-ADC group [10-12], consistent with the current study (Table 1). Furthermore, for the first time, our study shows that EGFRmutated non-ADC patients are more likely to have MPE and distant metastasis. ADC seems to be most commonly associated with MPE, which typically occurs in peripheral lesions [13,14]. However, it is known that the probability of MPE is also higher in LCLC, NSCLC NOS (not otherwise specified), and undifferentiated cases [15]. EGFR-mutated ADC patients with MPE had a higher rate of L858R mutation, which may play a role in the development of MPE [16].

Regarding distant metastasis, some studies have shown that the most frequent metastatic site of NSCLC is the bone, followed by the lung, brain, liver, and adrenal glands, and the most common combinations for two-site metastasis for SCC and LCLC were the bone and liver. On the other hand, lung and brain metastasis occurs more in EGFR-mutated NSCLC patients than in EGFR-wild type patients [17-20]. In any case, several studies have reported that liver metastasis has a poorer prognosis than other metastatic patterns [21,22]. In addition, liver metastasis may be related to exon 21 L858R [23].
The median OS for EGFR-mutated ADC patients treated with EGFRTKI is known to be 21.6-34.8 months [2,24-29]. In this study, the median OS for such patients was similar (29.5 months). The RR and median OS for EGFR-mutated non-ADC patients treated with EGFR-TKIs were reported to be inferior, at $25 \%-32 \%$ and 14.6 months, respectively $[6,7,30]$; in the present study, the RR for first use of EGFR-TKI was $51.6 \%$ and the median OS was 25.5 months. Furthermore, the median OS for EGFR-mutated non-ADC patients with 19 del (not reached) was significantly longer than that for patients with the L858R mutation (15.5 months).

This study shows that: 1) EGFR-mutated non-ADC patients are more likely to have MPE and distant metastasis. 2) EGFR-mutated non-ADC patients with the 19 del mutation can obtain clinical benefit from firstgeneration EGFR-TKI treatment.

Patients with L858R mutations will have a longer OS if administered first-generation EGFR-TKIs than if they do not receive them, but this OS will still be shorter than that of patents with the 19 del mutation (Fig. 3B). The efficacy of first-generation EGFR-TKIs had nothing to do with the type of EGFR mutation (Table 2). Furthermore, there was no significant difference in patient characteristics between non-ADC patients who either had 19 del or L858R mutation (Table 3). This indicates that patients with L858R mutations have a poor prognosis regardless of the efficacy of EGFR-TKIs or patient characteristics. These results are supported by preclinical studies that have demonstrated that 19 del and L858R have distinct biological properties that may affect the efficacy of EGFR-TKIs [31]. 
Table 2

Comparison of patient characteristics in EGFR-mutated non-adenocarcinoma between the response and non-response groups for treatment with first-generation EGFR-TKIs.

\begin{tabular}{|c|c|c|c|}
\hline Characteristics & $\mathrm{CR}+\mathrm{PR}(\mathrm{n}=34)$ & $\mathrm{SD}+\mathrm{PD}(\mathrm{n}=25)$ & $P$ value \\
\hline Age (yr) & & & 0.633 \\
\hline Median (range) & $67.5(32-84)$ & $70.0(49-88)$ & \\
\hline Gender & & & 0.608 \\
\hline Male & $18(52.9 \%)$ & $15(60 \%)$ & \\
\hline Female & $16(47.1 \%)$ & $10(40 \%)$ & \\
\hline Smoking history & & & 0.122 \\
\hline Never & $19(55.9 \%)$ & $12(48 \%)$ & \\
\hline Former & $14(41.2 \%)$ & $8(32 \%)$ & \\
\hline Current & $1(2.9 \%)$ & $5(20 \%)$ & \\
\hline PS (ECOG) & & & 0.841 \\
\hline $0,1,2$ & $30(88.2 \%)$ & $25(100 \%)$ & \\
\hline 3,4 & $4(11.8 \%)$ & $0(0 \%)$ & \\
\hline Malignant pleural effusion & & & 1 \\
\hline yes & $26(76.5 \%)$ & $20(80 \%)$ & \\
\hline no & $8(23.5 \%)$ & $5(20 \%)$ & \\
\hline Distant metastasis & & & 0.494 \\
\hline yes & $27(79.4 \%)$ & $22(88 \%)$ & \\
\hline no & $7(20.6 \%)$ & $3(12 \%)$ & \\
\hline Lung metastasis & & & 0.493 \\
\hline yes & $6(17.6 \%)$ & $4(16 \%)$ & \\
\hline no & $28(82.4 \%)$ & $21(84 \%)$ & \\
\hline Liver metastasis & & & 0.191 \\
\hline yes & $4(11.8 \%)$ & $4(16 \%)$ & \\
\hline no & $30(88.2 \%)$ & $21(84 \%)$ & \\
\hline Bone metastasis & & & 0.484 \\
\hline yes & $44.1(45.1 \%)$ & $12(48 \%)$ & \\
\hline no & $55.9(54.9 \%)$ & $13(52 \%)$ & \\
\hline Brain metastasis & & & 0.258 \\
\hline yes & $10(29.4 \%)$ & $5(20 \%)$ & \\
\hline no & $24(70.6 \%)$ & $20(80 \%)$ & \\
\hline Adrenal metastasis & & & 0.371 \\
\hline yes & $2(5.9 \%)$ & $4(16 \%)$ & \\
\hline no & $32(94.1 \%)$ & $21(84 \%)$ & \\
\hline Types of EGFR mutation & & & 0.511 \\
\hline 19 del & $17(50 \%)$ & $9(36 \%)$ & \\
\hline L858R & $15(44.1 \%)$ & $15(60 \%)$ & \\
\hline Others & $2(5.9 \%)$ & $1(4 \%)$ & \\
\hline
\end{tabular}

Abbreviations: EGFR, epidermal growth factor receptor; yr, year; PS, performance status; 19 del, exon 19 deletion mutation; L858R, exon 21 L858R mutation; Adeno, adenocarcinoma.

A major limitation of this study was that data were available only for gefitinib and erlotinib (which are first-generation EGFR-TKIs). Some patients may have been treated with afatinib (a second-generation EGFR-TKI) in this study, but we could not evaluate the efficacy of afatinib because the related data were input as "others treatments." This study also had several minor limitations, such as it being a retrospective study and having no access to the details of treatment lines and laboratory data for each patient.

Recently, osimertinib (a third-generation EGFR-TKI) has been approved as a first-line treatment for EGFR-mutated advanced NSCLC [32]. However, patients with L858R mutations treated with osimertinib did not exhibit significantly better OS than patients treated with firstgeneration EGFR-TKIs [33].

It is known that afatinib might not improve the OS of EGFR L858Rpositive NSCLC patients, whereas dacomitinib (a second-generation EGFR-TKI) does so [34-36]. Previous studies have claimed that patients with L858R mutations have more non-classical mutations (compound mutations) than those with 19 del, which could be the reason for the L858R mutation being associated with a poor clinical outcome [37]. Second-generation EGFR-TKIs are known to be more effective for patients with non-classical mutations lacking 19 del or L858R [38,39]. We did not estimate the ratio of compound mutations; however, treatment with second-generation EGFR-TKIs, especially dacomitinib, may be more effective for patients with L858R mutations.

Recent trials, such as ATLANTIC and IMpower150, showed that
Table 3

Comparison of patients characteristics between EGFR-mutated non-adenocarcinoma patients with exon 19 deletion and those with exon 21 L858R mutation.

\begin{tabular}{|c|c|c|c|}
\hline Characteristics & 19 del $(\mathrm{n}=30)$ & L858R ( $\mathrm{n}=32)$ & $P$ value \\
\hline Age (yr) & & & 0.156 \\
\hline Median (range) & $68.5(32-82)$ & $71.5(49-88)$ & \\
\hline Gender & & & 0.317 \\
\hline Male & $19(63.3 \%)$ & $16(50 \%)$ & \\
\hline Female & $11(36.7 \%)$ & $16(50 \%)$ & \\
\hline Smoking history & & & 0.611 \\
\hline Never & $14(46.7 \%)$ & 19 (59.4 \%) & \\
\hline Former & $13(43.3 \%)$ & $10(31.3 \%)$ & \\
\hline Current & $3(10 \%)$ & $3(9.4 \%)$ & \\
\hline PS (ECOG) & & & 0.613 \\
\hline $0,1,2$ & $29(96.7 \%)$ & $29(90.6 \%)$ & \\
\hline 3,4 & $1(3.3 \%)$ & $3(9.4 \%)$ & \\
\hline Malignant pleural effusion & & & 0.537 \\
\hline yes & $5(16.7 \%)$ & $8(25 \%)$ & \\
\hline no & $25(83.3 \%)$ & $24(75 \%)$ & \\
\hline Distant metastasis & & & 0.502 \\
\hline yes & $24(80 \%)$ & $28(87.5 \%)$ & \\
\hline no & $6(20 \%)$ & $4(12.5 \%)$ & \\
\hline Lung metastasis & & & 1 \\
\hline yes & $5(16.7 \%)$ & $6(18.8 \%)$ & \\
\hline no & $25(83.3 \%)$ & $26(81.3 \%)$ & \\
\hline Liver metastasis & & & 0.511 \\
\hline yes & $4(13.3 \%)$ & $7(21.9 \%)$ & \\
\hline no & $26(86.7 \%)$ & 25 (78.1\%) & \\
\hline Bone metastasis & & & 0.446 \\
\hline yes & $13(43.3 \%)$ & $18(56.3 \%)$ & \\
\hline no & $17(56.7 \%)$ & $14(43.8 \%)$ & \\
\hline Brain metastasis & & & 0.775 \\
\hline yes & $7(23.3 \%)$ & $9(28.1 \%)$ & \\
\hline no & $23(76.7 \%)$ & $23(71.9 \%)$ & \\
\hline Adrenal metastasis & & & 0.672 \\
\hline yes & $2(6.7 \%)$ & $4(12.5 \%)$ & \\
\hline no & $28(93.3 \%)$ & $28(87.5 \%)$ & \\
\hline
\end{tabular}

Abbreviations: yr, year; PS, performance status; 19 del, exon 19 deletion mutation; L858R, exon 21 L858R mutation.

some EGFR mutant lung cancers respond to immune-checkpoint inhibitors (ICIs) [40,41]. Specifically, 19 del tumors had a worse outcome, whereas L858R tumors had RR and OS similar to those for an EGFR-wild type lung cancer population [42].

Our study also shows that EGFR-mutated non-ADC patients are likely to have MPE and distant metastasis. Given that L858R may be related to MPE and liver metastasis, we can suggest adding an angiogenesis inhibitor, such as ramucirumab, to EGFR-TKIs for EGFR L858R positive non-ADC patients $[43,44]$.

Overall, EGFR-mutated non-ADC patients were more likely to have MPE and distant metastasis, including liver metastasis, which may be related to L858R mutations.

Both ADC and EGFR del19-positive non-ADC patients can obtain clinical benefit from EGFR-TKIs; however, EGFR L858R-positive nonADC patients may not have the same OS extension. Therefore, we suggest using another treatment for these patients besides the conventional treatment, for example, using second-generation EGFR-TKIs, ICIs, or adding an angiogenesis inhibitor. Clinical trials should be undertaken to evaluate the efficacy of these treatments for EGFR L858R-positive non-ADC patients.

\section{Authorship contributions}

Conception and design of study: K.Kobayashi, K.S., and Y.S;

Acquisition of data: K.Kobayashi, K.S., K.F., Y.S., I.S., T.S., K.Takayama, A.U., I.S., K.Kiura, K.Takahashi, N.Y., Y.T., E.M., M.O., and I.Y.;

Analysis and/or interpretation of data: K.Kobayashi, Y.S., and E.M. Drafting the manuscript: K.Kobayashi; 
Revising the manuscript critically for important intellectual content: K.Kobayashi, K.S., and Y.S.

Approval of the version of the manuscript to be published (the names of all authors must be listed): K.Kobayashi, K.S., K.F., Y.S., I.S., T.S., K.Takayama, A.U., I.S., K.Kiura, K.Takahashi, N.Y., Y.T., E.M., M.O., and I.Y.

\section{Transparency document}

The Transparency document associated with this article can be found in the online version.

\section{Declaration of Competing Interest}

All the authors declare that they have no conflict of interest related to this study.

\section{Acknowledgments}

The authors wish to thank all the contributors at the participating institutions. The Japanese Joint Committee of Lung Cancer Registry and this study were supported by The Japan Lung Cancer Society, The Japanese Respiratory Society, and The Japan Society for Respiratory Endoscopy. We would like to thank Editage (www.editage.com) for English language editing.

\section{References}

[1] T.J. Lynch, D.W. Bell, R. Sordella, S. Gurubhagavatula, R.A. Okimoto, B.W. Brannigan, P.L. Harris, S.M. Haserlat, J.G. Supko, F.G. Haluska, D.N. Louis, D.C. Christiani, J. Settleman, D.A. Haber, Activating mutations in the epidermal growth factor receptor underlying responsiveness of non-small-cell lung cancer to gefitinib, N. Engl. J. Med. 350 (21) (2004) 2129-2139.

[2] T.S. Mok, Y.L. Wu, S. Thongprasert, C.H. Yang, D.T. Chu, N. Saijo, P. Sunpaweravong, B. Han, B. Margono, Y. Ichinose, Y. Nishiwaki, Y. Ohe, J.J. Yang, B. Chewaskulyong, H. Jiang, E.L. Duffield, C.L. Watkins, A.A. Armour, M. Fukuoka, Gefitinib or carboplatin-paclitaxel in pulmonary adenocarcinoma, N Engl. J. Med. 361 (10) (2009) 947-957.

[3] M. Maemondo, A. Inoue, K. Kobayashi, S. Sugawara, S. Oizumi, H. Isobe, A. Gemma, M. Harada, H. Yoshizawa, I. Kinoshita, Y. Fujita, S. Okinaga, H. Hirano, K. Yoshimori, T. Harada, T. Ogura, M. Ando, H. Miyazawa, T. Tanaka, Y. Saijo, K. Hagiwara, S. Morita, T. Nukiwa, Gefitinib or chemotherapy for non-small-cell lung cancer with mutated EGFR, N. Engl. J. Med. 362 (25) (2010) 2380-2388.

[4] J.G. Paez, P.A. Janne, J.C. Lee, S. Tracy, H. Greulich, S. Gabriel, P. Herman, F.J. Kaye, N. Lindeman, T.J. Boggon, K. Naoki, H. Sasaki, Y. Fujii, M.J. Eck, W.R. Sellers, B.E. Johnson, M. Meyerson, EGFR mutations in lung cancer: correlation with clinical response to gefitinib therapy, Science 304 (5676) (2004) $1497-1500$.

[5] T.Y. Chou, C.H. Chiu, L.H. Li, C.Y. Hsiao, C.Y. Tzen, K.T. Chang, Y.M. Chen, R.P. Perng, S.F. Tsai, C.M. Tsai, Mutation in the tyrosine kinase domain of epidermal growth factor receptor is a predictive and prognostic factor for gefitinib treatment in patients with non-small cell lung cancer, Clin. Cancer Res. 11 (10) (2005) 3750-3757.

[6] T. Shukuya, T. Takahashi, R. Kaira, A. Ono, Y. Nakamura, A. Tsuya, H. Kenmotsu, T. Naito, K. Kaira, H. Murakami, M. Endo, K. Takahashi, N. Yamamoto, Efficacy of gefitinib for non-adenocarcinoma non-small-cell lung cancer patients harboring epidermal growth factor receptor mutations: a pooled analysis of published reports, Cancer Sci. 102 (5) (2011) 1032-1037.

[7] A. Hata, N. Katakami, H. Yoshioka, K. Kunimasa, S. Fujita, R. Kaji, K. Notohara, Y. Imai, R. Tachikawa, K. Tomii, Y. Korogi, M. Iwasaku, A. Nishiyama, T. Ishida, How sensitive are epidermal growth factor receptor-tyrosine kinase inhibitors for squamous cell carcinoma of the lung harboring EGFR gene-sensitive mutations? J. Thorac. Oncol. 8 (1) (2013) 89-95.

[8] N. Sawabata, E. Miyaoka, H. Asamura, Y. Nakanishi, K. Eguchi, M. Mori, H. Nomori, Y. Fujii, M. Okumura, K. Yokoi, Japanese lung cancer registry study of 11,663 surgical cases in 2004: demographic and prognosis changes over decade, J. Thorac. Oncol. 6 (7) (2011) 1229-1235.

[9] P. Therasse, S.G. Arbuck, E.A. Eisenhauer, J. Wanders, R.S. Kaplan, L. Rubinstein, J. Verweij, M. Van Glabbeke, A.T. van Oosterom, M.C. Christian, S.G. Gwyther, New guidelines to evaluate the response to treatment in solid tumors. European organization for research and treatment of cancer, national cancer institute of the United States, national cancer institute of Canada, J. Natl. Cancer Inst. 92 (3) (2000) 205-216.

[10] H.H. McDuffie, D.J. Klaassen, J.A. Dosman, Female-male differences in patients with primary lung cancer, Cancer 59 (10) (1987) 1825-1830.

[11] H.H. McDuffie, D.J. Klaassen, J.A. Dosman, Determinants of cell type in patients with cancer of the lungs, Chest 98 (5) (1990) 1187-1193.
[12] S. Watanabe, S. Tsugane, H. Arimoto, Y. Shimosato, K. Suemasu, H. Arai, Y. Urano, Trend of lung cancers in the national cancer center of Japan and comparison with that of Japanese pathological autopsy records, Jpn. J. Cancer Res. 78 (5) (1987) 460-466.

[13] D.R. Irani, R.D. Underwood, E.H. Johnson, S.D. Greenberg, Malignant pleural effusions. A clinical cytopathologic study, Arch. Intern. Med. 147 (6) (1987) 1133-1136.

[14] B. Chernow, S.A. Sahn, Carcinomatous involvement of the pleura: an analysis of 96 patients, Am. J. Med. 63 (5) (1977) 695-702.

[15] D. Morgensztern, S. Waqar, J. Subramanian, K. Trinkaus, R. Govindan, Prognostic impact of malignant pleural effusion at presentation in patients with metastatic non-small-cell lung cancer, J. Thorac. Oncol. 7 (10) (2012) 1485-1489.

[16] S.G. Wu, C.J. Yu, M.F. Tsai, W.Y. Liao, C.H. Yang, I.S. Jan, P.C. Yang, J.Y. Shih, Survival of lung adenocarcinoma patients with malignant pleural effusion, Eur. Respir. J. 41 (6) (2013) 1409-1418.

[17] F.C. Detterbeck, D.J. Boffa, A.W. Kim, L.T. Tanoue, The eighth edition lung cancer stage classification, Chest 151 (1) (2017) 193-203.

[18] M. Riihimaki, A. Hemminki, M. Fallah, H. Thomsen, K. Sundquist, J. Sundquist, K. Hemminki, Metastatic sites and survival in lung cancer, Lung Cancer 86 (1) (2014) 78-84.

[19] Y. Ren, C. Dai, H. Zheng, F. Zhou, Y. She, G. Jiang, K. Fei, P. Yang, D. Xie, C. Chen, Prognostic effect of liver metastasis in lung cancer patients with distant metastasis, Oncotarget 7 (33) (2016) 53245-53253.

[20] Z. Xu, Q. Yang, X. Chen, L. Zheng, L. Zhang, Y. Yu, M. Chen, Q. You, J. Sun, Clinical associations and prognostic value of site-specific metastases in non-small cell lung cancer: a population-based study, Oncol. Lett. 17 (6) (2019) 5590-5600.

[21] K.L. Wu, M.J. Tsai, C.J. Yang, W.A. Chang, J.Y. Hung, C.J. Yen, C.H. Shen, T.Y. Kuo, J.Y. Lee, S.H. Chou, T.C. Liu, I.W. Chong, M.S. Huang, Liver metastasis predicts poorer prognosis in stage IV lung adenocarcinoma patients receiving first-line gefitinib, Lung Cancer 88 (2) (2015) 187-194.

[22] P. Mordant, A. Arame, F. De Dominicis, C. Pricopi, C. Foucault, A. Dujon, F. Le Pimpec-Barthes, M. Riquet, Which metastasis management allows long-term survival of synchronous solitary M1b non-small cell lung cancer? Eur. J. Cardiothorac Surg. 41 (3) (2012) 617-622.

[23] F. Hsu, A. De Caluwe, D. Anderson, A. Nichol, T. Toriumi, C. Ho, Patterns of spread and prognostic implications of lung cancer metastasis in an era of driver mutations, Curr. Oncol. 24 (4) (2017) 228-233.

[24] J.Y. Han, K. Park, S.W. Kim, D.H. Lee, H.Y. Kim, H.T. Kim, M.J. Ahn, T. Yun, J.S. Ahn, C. Suh, J.S. Lee, S.J. Yoon, J.H. Han, J.W. Lee, S.J. Jo, J.S. Lee, FirstSIGNAL: first-line single-agent iressa versus gemcitabine and cisplatin trial in neversmokers with adenocarcinoma of the lung, J. Clin. Oncol. 30 (10) (2012) 1122-1128.

[25] E. Miyauchi, A. Inoue, K. Kobayashi, M. Maemondo, S. Sugawara, S. Oizumi, H. Isobe, A. Gemma, Y. Saijo, H. Yoshizawa, K. Hagiwara, T. Nukiwa, Efficacy of chemotherapy after first-line gefitinib therapy in EGFR mutation-positive advanced non-small cell lung cancer-data from a randomized Phase III study comparing gefitinib with carboplatin plus paclitaxel (NEJ002), Jpn. J. Clin. Oncol. 45 (7) (2015) 670-676.

[26] H. Akamatsu, A. Inoue, T. Mitsudomi, K. Kobayashi, K. Nakagawa, K. Mori, T. Nukiwa, Y. Nakanishi, N. Yamamoto, Interstitial lung disease associated with gefitinib in Japanese patients with EGFR-mutated non-small-cell lung cancer: combined analysis of two Phase III trials (NEJ 002 and WJTOG 3405), Jpn. J. Clin. Oncol. 43 (6) (2013) 664-668.

[27] R. Rosell, E. Carcereny, R. Gervais, A. Vergnenegre, B. Massuti, E. Felip, R. Palmero, R. Garcia-Gomez, C. Pallares, J.M. Sanchez, R. Porta, M. Cobo, P. Garrido, F. Longo, T. Moran, A. Insa, F. De Marinis, R. Corre, I. Bover, A. Illiano, E. Dansin, J. de Castro, M. Milella, N. Reguart, G. Altavilla, U. Jimenez, M. Provencio, M.A. Moreno, J. Terrasa, J. Munoz-Langa, J. Valdivia, D. Isla, M. Domine, O. Molinier, J. Mazieres, N. Baize, R. Garcia-Campelo, G. Robinet, D. Rodriguez-Abreu, G. Lopez-Vivanco, V. Gebbia, L. Ferrera-Delgado, P. Bombaron, R. Bernabe, A. Bearz, A. Artal, E. Cortesi, C. Rolfo, M. Sanchez-Ronco, A. Drozdowskyj, C. Queralt, I. de Aguirre, J.L. Ramirez, J.J. Sanchez, M.A. Molina, M. Taron, L. Paz Ares, Erlotinib versus standard chemotherapy as first-line treatment for European patients with advanced EGFR mutation-positive non-small-cell lung cancer (EURTAC): a multicentre, open-label, randomised phase 3 trial, Lancet Oncol. 13 (3) (2012) 239-246.

[28] C. Zhou, Y.L. Wu, G. Chen, J. Feng, X.Q. Liu, C. Wang, et al., Erlotinib versus chemotherapy as first-line treatment for patients with advanced EGFR mutationpositive non-small-cell lung cancer (OPTIMAL, CTONG-0802): a multicentre, openlabel, randomised, phase 3 study, Lancet Oncol. 12 (8) (2011) 735-742.

[29] Y.L. Wu, C. Zhou, C.K. Liam, G. Wu, X. Liu, Z. Zhong, S. Lu, Y. Cheng, B. Han, L. Chen, C. Huang, S. Qin, Y. Zhu, H. Pan, H. Liang, E. Li, G. Jiang, S.H. How, M.C. Fernando, Y. Zhang, F. Xia, Y. Zuo, First-line erlotinib versus gemcitabine/ cisplatin in patients with advanced EGFR mutation-positive non-small-cell lung cancer: analyses from the phase III, randomized, open-label, ENSURE study, Ann. Oncol. 26 (9) (2015) 1883-1889.

[30] J. Xu, Y. Zhang, B. Jin, T. Chu, X. Dong, H. Yang, D. Wu, Y. Lou, X. Zhang, H. Wang, B. Han, Efficacy of EGFR tyrosine kinase inhibitors for non-adenocarcinoma lung cancer patients harboring EGFR-sensitizing mutations in China, J. Cancer Res. Clin. Oncol. 142 (6) (2016) 1325-1330.

[31] J.Q. Zhu, W.Z. Zhong, G.C. Zhang, R. Li, X.C. Zhang, A.L. Guo, Y.F. Zhang, S.J. An, T.S. Mok, Y.L. Wu, Better survival with EGFR exon 19 than exon 21 mutations in gefitinib-treated non-small cell lung cancer patients is due to differential inhibition of downstream signals, Cancer Lett. 265 (2) (2008) 307-317.

[32] J.C. Soria, Y. Ohe, J. Vansteenkiste, T. Reungwetwattana, B. Chewaskulyong, K.H. Lee, A. Dechaphunkul, F. Imamura, N. Nogami, T. Kurata, I. Okamoto, C. Zhou, 
B.C. Cho, Y. Cheng, E.K. Cho, P.J. Voon, D. Planchard, W.C. Su, J.E. Gray, S.M. Lee, R. Hodge, M. Marotti, Y. Rukazenkov, S.S. Ramalingam, Osimertinib in untreated EGFR-Mutated advanced non-small-cell lung cancer, N. Engl. J. Med. 378 (2) (2018) 113-125.

[33] S.S. Ramalingam, J. Vansteenkiste, D. Planchard, B.C. Cho, J.E. Gray, Y. Ohe, C. Zhou, T. Reungwetwattana, Y. Cheng, B. Chewaskulyong, R. Shah, M. Cobo, K.H. Lee, P. Cheema, M. Tiseo, T. John, M.C. Lin, F. Imamura, T. Kurata, A. Todd, R. Hodge, M. Saggese, Y. Rukazenkov, J.C. Soria, Overall survival with osimertinib in untreated, EGFR-mutated advanced NSCLC, N. Engl. J. Med. 382 (1) (2020) $41-50$.

[34] J.C. Yang, Y.L. Wu, M. Schuler, M. Sebastian, S. Popat, N. Yamamoto, C. Zhou, C.P. Hu, K. O’Byrne, J. Feng, S. Lu, Y. Huang, S.L. Geater, K.Y. Lee, C.M. Tsai, V. Gorbunova, V. Hirsh, J. Bennouna, S. Orlov, T. Mok, M. Boyer, W.C. Su, K.H. Lee, T. Kato, D. Massey, M. Shahidi, V. Zazulina, L.V. Sequist, Afatinib versus cisplatinbased chemotherapy for EGFR mutation-positive lung adenocarcinoma (LUX-Lung 3 and LUX-Lung 6): analysis of overall survival data from two randomised, phase 3 trials, Lancet Oncol. 16 (2) (2015) 141-151.

[35] T. Kato, H. Yoshioka, I. Okamoto, A. Yokoyama, T. Hida, T. Seto, K. Kiura, D. Massey, Y. Seki, N. Yamamoto, Afatinib versus cisplatin plus pemetrexed in Japanese patients with advanced non-small cell lung cancer harboring activating EGFR mutations: subgroup analysis of LUX-Lung 3, Cancer Sci. 106 (9) (2015) 1202-1211.

[36] Y.L. Wu, Y. Cheng, X. Zhou, K.H. Lee, K. Nakagawa, S. Niho, F. Tsuji, R. Linke, R. Rosell, J. Corral, M.R. Migliorino, A. Pluzanski, E.I. Sbar, T. Wang, J.L. White, S. Nadanaciva, R. Sandin, T.S. Mok, Dacomitinib versus gefitinib as first-line treatment for patients with EGFR-mutation-positive non-small-cell lung cancer (ARCHER 1050): a randomised, open-label, phase 3 trial, Lancet Oncol. 18 (11) (2017) 1454-1466.

[37] E.Y. Kim, E.N. Cho, H.S. Park, J.Y. Hong, S. Lim, J.P. Youn, S.Y. Hwang, Y.S. Chang, Compound EGFR mutation is frequently detected with co-mutations of actionable genes and associated with poor clinical outcome in lung adenocarcinoma, Cancer Biol. Ther. 17 (3) (2016) 237-245.

[38] S. Kohsaka, M. Nagano, T. Ueno, Y. Suehara, T. Hayashi, N. Shimada, K. Takahashi, K. Suzuki, K. Takamochi, F. Takahashi, H. Mano, A method of high-throughput functional evaluation of EGFR gene variants of unknown significance in cancer, Sci. Transl. Med. 9 (416) (2017).

[39] Y.C. Shen, G.C. Tseng, C.Y. Tu, W.C. Chen, W.C. Liao, W.C. Chen, C.H. Li, H.J. Chen, T.C. Hsia, Comparing the effects of afatinib with gefitinib or Erlotinib in patients with advanced-stage lung adenocarcinoma harboring non-classical epidermal growth factor receptor mutations, Lung Cancer 110 (2017) 56-62.

[40] M.C. Garassino, B.C. Cho, J.H. Kim, J. Mazieres, J. Vansteenkiste, H. Lena, J. Corral Jaime, J.E. Gray, J. Powderly, C. Chouaid, P. Bidoli, P. Wheatley-Price, K. Park, R.A. Soo, Y. Huang, C. Wadsworth, P.A. Dennis, N.A. Rizvi, Durvalumab as thirdline or later treatment for advanced non-small-cell lung cancer (ATLANTIC): an open-label, single-arm, phase 2 study, Lancet Oncol. 19 (4) (2018) 521-536.

[41] M. Reck, T.S.K. Mok, M. Nishio, R.M. Jotte, F. Cappuzzo, F. Orlandi, D. Stroyakovskiy, N. Nogami, D. Rodriguez-Abreu, D. Moro-Sibilot, C.A. Thomas, F. Barlesi, G. Finley, A. Lee, S. Coleman, Y. Deng, M. Kowanetz, G. Shankar, W. Lin, M.A. Socinski, Atezolizumab plus bevacizumab and chemotherapy in non-small-cell lung cancer (IMpower150): key subgroup analyses of patients with EGFR mutations or baseline liver metastases in a randomised, open-label phase 3 trial, Lancet Respir. Med. 7 (5) (2019) 387-401.

[42] K. Hastings, H.A. Yu, W. Wei, F. Sanchez-Vega, M. DeVeaux, J. Choi, H. Rizvi, A. Lisberg, A. Truini, C.A. Lydon, Z. Liu, B.S. Henick, A. Wurtz, G. Cai, A.J. Plodkowski, N.M. Long, D.F. Halpenny, J. Killam, I. Oliva, N. Schultz G.J. Riely, M.E. Arcila, M. Ladanyi, D. Zelterman, R.S. Herbst, S.B. Goldberg, M.M. Awad, E B. Garon, S. Gettinger, M.D. Hellmann, K. Politi, EGFR mutation subtypes and response to immune checkpoint blockade treatment in non-small-cell lung cancer, Ann. Oncol. 30 (8) (2019) 1311-1320.

[43] A. Sandler, R. Gray, M.C. Perry, J. Brahmer, J.H. Schiller, A. Dowlati, R. Lilenbaum, D.H. Johnson, Paclitaxel-carboplatin alone or with bevacizumab for non-small-cell lung cancer, N. Engl. J. Med. 355 (24) (2006) 2542-2550.

[44] K. Nakagawa, E.B. Garon, T. Seto, M. Nishio, S. Ponce Aix, L. Paz-Ares, C.H. Chiu, K. Park, S. Novello, E. Nadal, F. Imamura, K. Yoh, J.Y. Shih, K.H. Au, D. MoroSibilot, S. Enatsu, A. Zimmermann, B. Frimodt-Moller, C. Visseren-Grul, M. Reck, Ramucirumab plus erlotinib in patients with untreated, EGFR-mutated, advanced non-small-cell lung cancer (RELAY): a randomised, double-blind, placebo-controlled, phase 3 trial, Lancet Oncol. (2019). 